\title{
Search and Rescue and Remote Medical Evacuation in a Norwegian Setting: Comparison of Two Systems
}

\author{
Bjørn O. Reid, $\mathrm{MD}^{1,2}$; Helge Haugland, $\mathrm{MD}^{1,3}$; Marius Rehn, MD, $\mathrm{PhD}^{3,4,5}$; Oddvar Uleberg, $\mathrm{MD}^{1,3}$; \\ Andreas J. Krüger, $\mathrm{MD}, \mathrm{PhD}^{1,3}$ \\ ${ }^{1}$ Department of Emergency Medicine and Prehospital Services, St. Olav's University Hospital, Trondheim, Norway; ${ }^{2}$ Medical Services, Norwegian \\ Armed Forces, Sessvollmoen, Norway; ${ }^{3}$ Department of Research and Development, Norwegian Air Ambulance Foundation, Oslo, Norway; \\ ${ }^{4}$ Prehospital Division, Air Ambulance Department, Oslo University Hospital, Oslo, Norway; ${ }^{5}$ Faculty of Health Sciences, University of Stavanger, \\ Stavanger, Norway
}

Introduction-Helicopter emergency medical services (HEMS) contribute to and complement other specialized search and rescue (SAR) services. Conversely, traditional SAR services perform medical evacuation (medevac), depending on crew, training, medical equipment, and procedures for interdisciplinary cooperation. We aim to describe and compare SAR and remote medevac mission characteristics in a military SAR helicopter system to a civilian HEMS operating in the same region.

Methods-Retrospective, observational study of SAR and remote medevac missions performed at a Norwegian military SAR helicopter and civilian HEMS base in the 5-y period from January 1, 2013 to December 31, 2017. Descriptive statistics and median values with interquartile range (IQR) were applied where appropriate. Comparisons were performed with the Mann-Whitney $U$ test.

Results-We included 721 missions. The SAR service performed 359 (50\%) missions, of which 237 (33\%) were SAR and $122(17 \%)$ were remote medevac missions. The HEMS service performed 85 (12\%) SAR and 277 (38\%) remote medevac missions. Median mission time for SAR missions was 152 (IQR 100-235) min for the SAR service and 57 (IQR 34-89) min for the HEMS service. Trauma was the dominating mechanism in $48 \%$ of patients, followed by medical conditions $(21 \%)$ and psychiatric disorders $(9 \%)$. Medevac patients in both services had a higher median National Advisory Committee for Aeronautics score of 3 (IQR 2-4) compared to 1 (IQR 0-3) in SAR missions $(P<0.05)$.

Conclusions - Both SAR and HEMS services perform SAR and remote medevac missions extensively and mission profiles vary.

Keywords: wilderness medicine, helicopter, emergency medical system

\section{Introduction}

In both civilian and military settings, helicopters are extensively deployed for the purpose of inserting and extracting personnel and equipment, in addition to other specialized roles. ${ }^{1-4}$ Search and rescue (SAR) and medical evacuation (medevac) capabilities are suited to use of rotary wing aircraft. ${ }^{5,6}$ Medevac of patients from remote or austere environments plays an important part in wilderness medicine, including evacuations from ship and offshore installations. $^{7,8}$ These evacuations have similarities with SAR

Corresponding author: Bjørn O. Reid, MD, Department of Emergency Medicine and Prehospital Services, Prinsesse Kristinas gate 3, AHL, St. Olav's University Hospital, NO-7030 Trondheim, Norway; e-mail: bjorn.ole.reid@stolav.no.

Submitted for publication October 2018.

Accepted for publication February 2019. missions in that both mission types often involve the identification and extrication of persons in environments that are considered potentially threatening or challenging to access. Terrain, weather, altitude, distance, and landing/takeoff conditions may pose specific challenges, and performance may be limited by helicopter type and equipment, crew composition, training, and system characteristics. ${ }^{9-11}$

The coordination and performance of SAR and medevac missions from remote areas may be challenging and often involves interdisciplinary cooperation across different services, including police, fire, and health services; the military; civilian institutions; and nongovernmental organizations. $^{12-16}$ Helicopter emergency medical services (HEMS) are embedded in many EMS systems and may contribute to or complement other specialized SAR services. ${ }^{17,18}$ Conversely, traditional SAR services may perform medevac missions, depending on crew, training, 
medical equipment, and procedures for interdisciplinary cooperation. These services have typically used both larger helicopters and crew and have traditionally been operated by the military. Certain countries, including those in the United Kingdom, have seen a transition in this respect, with outsourcing of SAR services to civilian contractors.

Researching the operative profile of different SAR concepts is important to better understand factors that may influence the planning for, coordination of, and execution of these complex missions and to optimally exploit available resources.

We aim to describe and compare SAR and remote medevac mission characteristics in a military SAR helicopter system with those in a civilian HEMS operating in the same region of Norway. Our hypothesis is that both services perform both types of missions extensively, but, that mission characteristics between the 2 services vary significantly.

\section{OPERATIONAL SETTING}

There are 6 SAR helicopter bases distributed throughout mainland Norway. They are under the jurisdiction of the Department of Justice but are operated by the Royal
Norwegian Air Force. During the study period, the SAR base at Ørland had a primary SAR responsibility for a catchment land area of $72,525 \mathrm{~km}^{2}$, consisting of a population of approximately 715,000 (Figure 1). In addition, it operates in the extensive offshore area off the Norwegian coast. The service operates a Westland Sea King, with a maximum flying time of $5.5 \mathrm{~h}$ and a crew of 6 consisting of 2 pilots, a flight engineer (winch operator), radar operator (winch operator), rescue man (paramedic), and doctor. The crew members are air force personnel, excepting the doctor, who is a civilian consultant anesthesiologist, in compliance with the same national standards that apply to all air ambulance doctors in Norway. ${ }^{19}$ The SAR helicopter is equipped with 2 rescue hoists, and both the rescue man and the doctor are trained to participate in helicopter hoist operations on both sea and land, including nighttime operations. In addition, all crew members have night vision goggles, and the radar operator operates a video/infrared detection pod.

Norwegian SAR missions are coordinated at the national level by 2 joint rescue coordination centers (JRCCs) in the north (Bod $\varnothing$ ) and south (Sola), enhanced by local rescue centrals in each police district. The JRCC may contact the

\section{Helicopter bases}

(H)

\section{Catchtment areas}

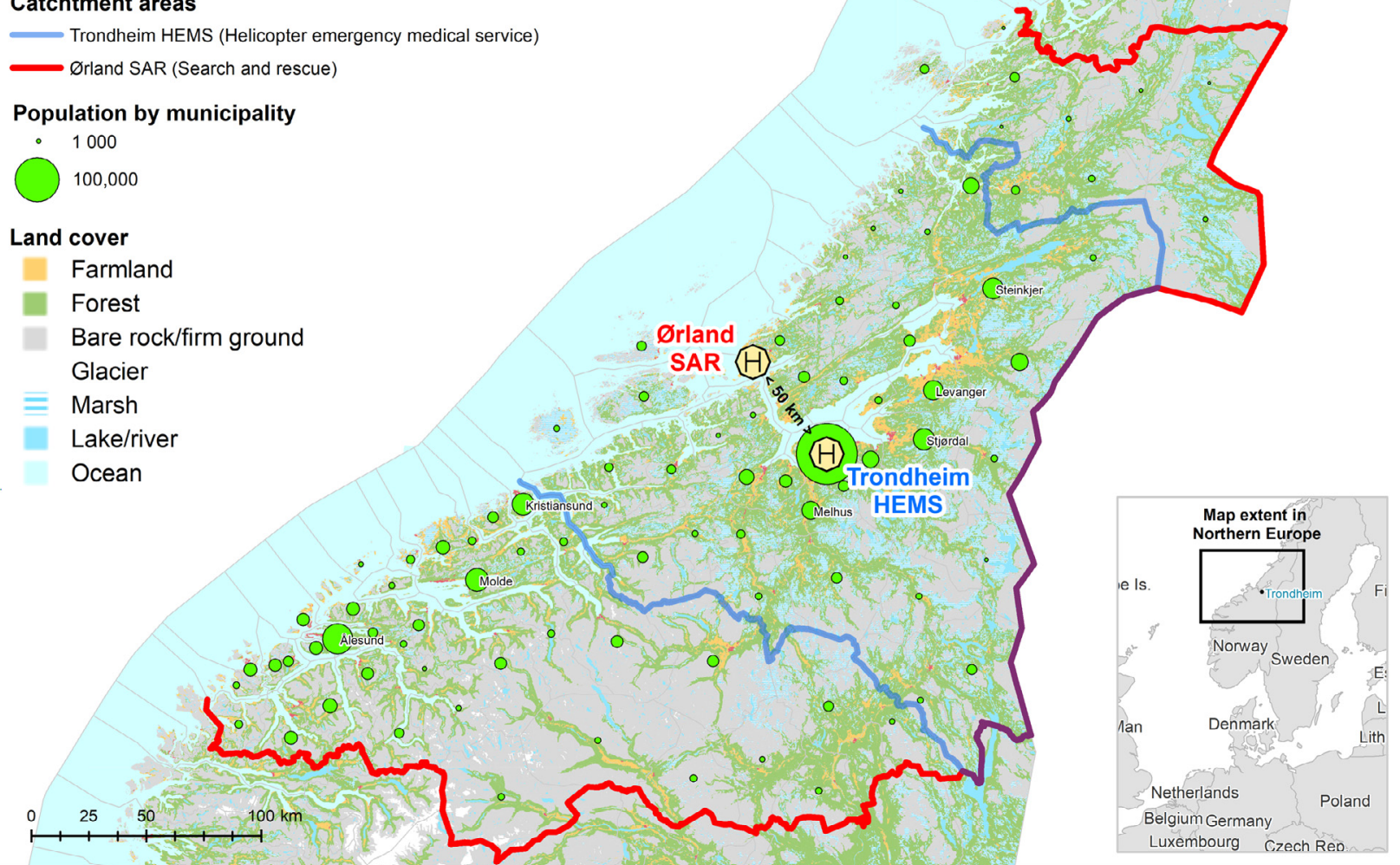

Figure 1. Flowchart of catchment areas of Trondheim helicopter emergency medical services and Ørland search and rescue service. 
SAR helicopter, which is primarily responsible for a designated area, but may also alert other helicopters, including air ambulance helicopters, which may be closer to a scene and can initiate SARs.

The Norwegian air ambulance network is a state-funded national service consisting of 12 HEMS (rotary wing) bases. ${ }^{1,20}$ The aforementioned 6 military SAR bases complement the civilian HEMS network. In addition, there are 7 fixed wing bases. During the study period, the HEMS base in Trondheim operated a Eurocopter EC 135 with a maximum flying time of $3.5 \mathrm{~h}$. The primary role of this HEMS helicopter is air ambulance missions with a catchment area of $30,989 \mathrm{~km}^{2}$ and a population of approximately 430,000 inhabitants (Figure 1). The crew consists of a pilot, a rescue man (paramedic), and a consultant anesthesiologist. HEMS missions are coordinated by the emergency medical communications centers (EMCC), and both HEMS and SAR helicopters may be dispatched to air ambulance missions. On dispatch, the crew of both services may consult JRCC and EMCC for further information pertaining to the mission. Missions may be cancelled for weather, technical, or operational reasons. In addition, the HEMS helicopter can perform and participate in SAR missions. All crew members have night vision goggles, and they can perform rescue operations over land or water using a static rope (human external cargo operations) during daylight hours. ${ }^{21}$ The HEMS helicopter has an $18.5 \mathrm{~km}$ flying limit from the coastline, implying that offshore SAR operations are only conducted by dedicated SAR units. Both HEMS and SAR helicopters can transport rescue divers, search dogs, and alpine rescue teams.

The SAR and HEMS helicopters in this study operate in the same region, with a distance of $50 \mathrm{~km}$ between the 2 bases. They are dispatched by the same JRCC and EMCC for that region.

Norway has 3 distinct emergency telephone numbers that the public may use to contact the police, fire department, or EMCC. Normally, air ambulance missions are activated when the public calls the specific emergency number for emergency medical conditions (113) and arrives directly at the local EMCC. SAR missions are often conveyed to JRCC via the EMCC or the regional police dispatch centers. The JRCC, EMCC, regional police dispatch, and fire dispatch centrals all have direct lines of communication, enabling an efficient handling of events between the available services.

\section{Methods}

\section{STUDY DESIGN}

This was a retrospective, observational study of SAR and remote medevac missions performed at a military SAR helicopter and civilian HEMS base in the 5-y period from January 1, 2013 to December 31, 2017. The SAR and HEMS doctors register patient and operational data from each mission into the same electronic patient record database (LabasNGRW, Normann IT, Version 6.5) using a predefined definition catalogue. A retrospective extraction of anonymized data was performed and subsequently analyzed in SPSS statistics, version 22 (IBM Corp, Armonk, NY).

A SAR mission was defined as a mission dispatched by the JRCC. The exception to this was offshore medevacs, which are dispatched by the JRCC, but in this study were classified as remote medevac missions. We also included SAR missions without patient contact, considering that many search missions can be very time-consuming but may not entail contact with a missing person/ object. Remote medevac missions were otherwise defined as missions in remote terrain dispatched by the EMCC. Only remote medevac missions with patient contact were included.

For the purpose of this study we chose to classify remote mission terrain in the manner described in Table 1.

A typical example of a SAR mission would be the search for a missing person or object of unknown exact location, as would be an evacuation of a person from a known environment that is considered austere. A remote medevac mission would be the evacuation of an injured or sick patient from a known location, typically inaccessible by road.

Variables included demographic and operational mission data and data depicting cooperation with other SAR or HEMS service and the use of hoist, sling/static rope, or "light on skid" for evacuation. Search time was defined as the time period of active search in a defined search area. Time for refueling was excluded. A negative search was defined as an established search mission that did not result in finding the person or object. Finding a deceased person was defined as a positive search. We included 721 missions in the study (Figure 2).

Patient variables included age, sex, medical procedures performed, and type of medical problem. A

Table 1. Definition of remote terrain

\begin{tabular}{ll}
\hline Rugged terrain & $\begin{array}{c}\text { Challenging topography characterized } \\
\text { by mountains/cliffs/forestation } \\
\text { Tsolated terrain }\end{array}$ \\
& $\begin{array}{c}\text { Topography characterized by remote- } \\
\text { ness in wilderness or on islands inac- } \\
\text { cessible by road }\end{array}$ \\
Inland water/coast & Topography characterized by rivers, \\
& lakes, fjords, and open waters within \\
& $18.5 \mathrm{~km}$ of coast \\
Offshore & Open waters beyond $18.5 \mathrm{~km}$ of \\
& coastline \\
\hline
\end{tabular}




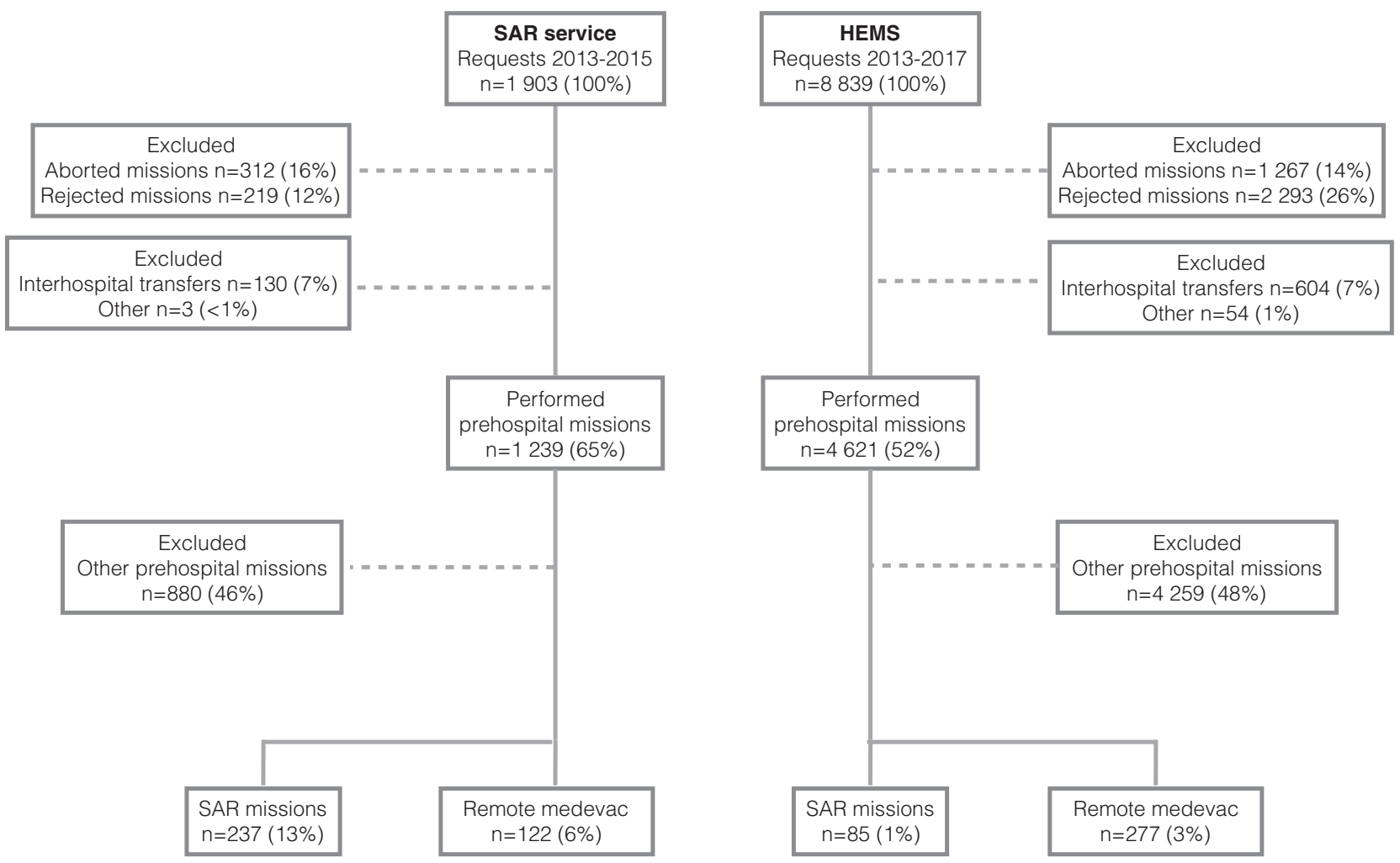

Figure 2. Flowchart of included missions.

psychiatric disorder was defined as a medical problem when there was sufficient suspicion of this condition, including severe emotional disorders and dementia. Patient severity was measured by applying National Advisory Committee for Aeronautics (NACA) score. This score is a compulsory scoring in Norwegian air ambulance patient documentation and has proven to be a reliable predictor of mortality. ${ }^{22}$ It is an 8-level scale $(0-7)$, with 0 signifying a person with no injuries or illness and 7 signifying a fatality.

We identified 624 patients with a recorded NACA score. These patients were included in the study (Table 2).

\section{STATISTICS AND ETHICS}

We applied descriptive statistics to describe the data, using frequencies, percentages, range, and median with interquartile range (IQR) where appropriate. Differences in mission distribution between services were compared using Pearson's $\chi^{2}$ test. Because the NACA score is an ordinal scale, we used the median as a measure of central tendency in these scores. The Mann-Whitney $U$ test was applied to compare NACA scores of services and mission types. Because of the nonnormal distribution of the data, the same test was applied to compare time measurements. The reporting of data was performed according to the Strengthening the Reporting of Observational Studies in Epidemiology guidelines. ${ }^{23}$

Study approval from the Regional Committee for Medical and Health Research Ethics of Central Norway (2018/43) was granted.

\section{Results}

The SAR service performed 359 (50\%) and HEMS 362 $(50 \%)$ of the included missions (Table 3 ). There were 47 recorded missions that included more than 1 patient. Trauma was the dominating mechanism in $48 \%$ of patients, followed by medical conditions (21\%) and psychiatric disorders (9\%) (Table 2). Fracture reductions were the most frequently performed advanced procedure $(6 \%)$, followed by endotracheal intubation $(3 \%)$.

There was a significantly higher $(P<0.05)$ NACA score (median 3 [IQR 2-4]) in the HEMS service compared to the SAR service (median 2 [IQR 0-3]). Medevac patients in both services were found to have a median NACA score of 3 (IQR 2-4) compared to 1 (IQR 0-3) in SAR missions $(P<0.05)$.

\section{Discussion}

This study found that a military SAR and civilian HEMS helicopter operating in the same region 
Table 2. Patient variables related to mission and service

\begin{tabular}{|c|c|c|c|c|}
\hline \multirow[t]{2}{*}{ Patient characteristics } & \multicolumn{2}{|c|}{ Search and rescue } & \multicolumn{2}{|c|}{ Remote medevac } \\
\hline & $S A R$ & $H E M S$ & $S A R$ & $H E M S$ \\
\hline Included patients, n (\%) & $197(32)$ & $22(3)$ & $126(20)$ & $279(45)$ \\
\hline NACA score, median (IQR) & $1(0-3)$ & $2(1-5)$ & $3(3-4)$ & $3(2-3)$ \\
\hline NACA score 7 (deceased), n (\%) & $30(5)$ & $4(<1)$ & $6(1)$ & $13(2)$ \\
\hline Male, $\mathrm{n}(\%)$ & $154(78)$ & $13(59)$ & $96(76)$ & $165(59)$ \\
\hline Plural persons, n (range) & $39(2-14)$ & $1(2)$ & $4(2-3)$ & $3(2)$ \\
\hline \multicolumn{5}{|l|}{ Dominating mechanism, $n(\%)$} \\
\hline Trauma & $52(8)$ & $13(2)$ & $61(10)$ & $173(28)$ \\
\hline Medical condition & $2(<1)$ & $2(<1)$ & $42(7)$ & $88(14)$ \\
\hline Psychiatric disorder & $43(7)$ & $6(<1)$ & $2(<1)$ & $2(<1)$ \\
\hline Surgical & $3(<1)$ & 0 & $17(3)$ & $11(2)$ \\
\hline Gynecology/Obstetrics & 0 & 0 & $1(<1)$ & $1(<1)$ \\
\hline Hypothermia & $28(9)$ & $1(<1)$ & $2(<1)$ & $4(<1)$ \\
\hline Missing & $69(11)$ & 0 & $1(1)$ & 0 \\
\hline \multicolumn{5}{|l|}{ Advanced procedure, $n(\%)$} \\
\hline Endotracheal intubation/ SAD & $2(<1)$ & $2(<1)$ & $6(1)$ & $11(2)$ \\
\hline Fracture reduction & $5(<1)$ & 0 & $8(1)$ & $26(4)$ \\
\hline Defibrillation & $1(<1)$ & $1(<1)$ & $3(<1)$ & $4(<1)$ \\
\hline Thoracocentesis & 0 & 0 & $1(<1)$ & 0 \\
\hline Mechanical chest compressions & $1(<1)$ & $2(<1)$ & $3(<1)$ & $2(<1)$ \\
\hline Antibiotics & 0 & 0 & $2(<1)$ & $1(<1)$ \\
\hline
\end{tabular}

SAR, search and rescue; HEMS, helicopter emergency medical service; NACA, National Advisory Committee for Aeronautics; IQR: Interquartile range; $\mathrm{SAD}$, supraglottic airway device.

Plural persons: more than 1 patient.

extensively perform both SAR and remote medevac missions. The military SAR helicopter performed longer searches, had longer missions times, and undertook a greater number of helicopter hoist operations, especially in rugged terrain. By contrast, the
HEMS service performed more remote medevac missions and advanced medical procedures. In addition, we observed seasonal variations for both services, most prominently for SAR missions during peak seasons in the spring and summer (Figure 3 ).

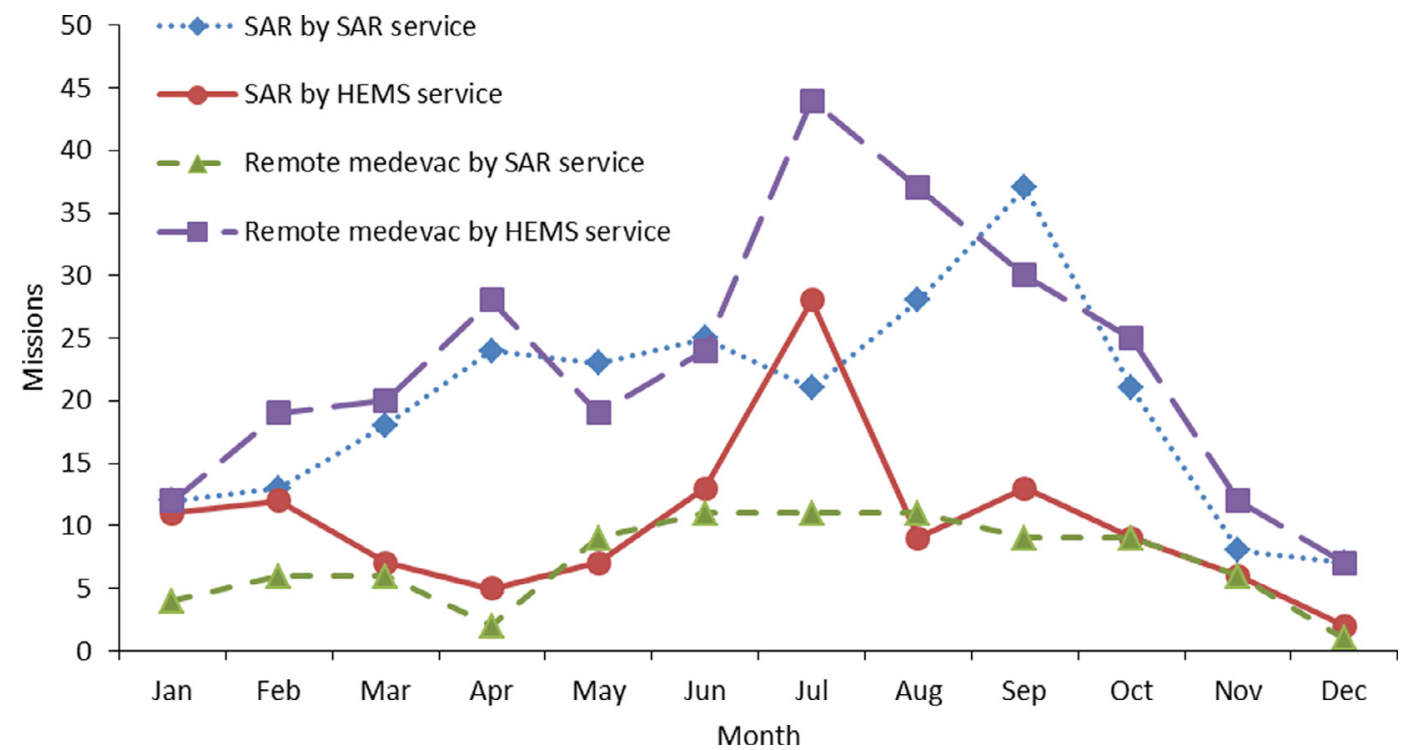

Figure 3. Mission frequency according to service, mission type, and calendar month. 
Table 3. Description of operational variables

\begin{tabular}{|c|c|c|c|c|c|c|c|}
\hline \multirow[t]{2}{*}{ Service } & \multicolumn{2}{|c|}{ Search and rescue } & \multirow[b]{2}{*}{$P^{*}$} & \multicolumn{2}{|c|}{ Remote medevac } & \multirow[b]{2}{*}{$P^{*}$} & \multirow[t]{2}{*}{ Total } \\
\hline & $S A R$ & $H E M S$ & & $S A R$ & $H E M S$ & & \\
\hline Missions, $\mathrm{n}(\%)$ & $237(33)$ & $85(12)$ & & $122(17)$ & $277(38)$ & & $\begin{array}{r}721(100) \\
{ }^{\dagger} \mathrm{P}<0.05\end{array}$ \\
\hline $\begin{array}{l}\text { Flying time to scene (min), } \\
\text { median (IQR) }\end{array}$ & $32(18-47)$ & $6(3-21)$ & $<0.05$ & $32(22-57)$ & $27(18-36)$ & $<0.05$ & N/A \\
\hline $\begin{array}{l}\text { Search time }(\mathrm{min}) \\
\text { median }(\mathrm{IQR})\end{array}$ & $38(10-116)$ & $22(12-39)$ & $<0.05$ & N/A & N/A & N/A & N/A \\
\hline $\begin{array}{l}\text { Mission time }(\mathrm{min}) \\
\text { median }(\mathrm{IQR})\end{array}$ & $152(100-235)$ & $57(34-89)$ & $<0.05$ & $138(107-175)$ & $95(68-122)$ & $<0.05$ & N/A \\
\hline Negative search, n (\%) & $86(12)$ & $49(7)$ & & 0 & 0 & & 135 (19) \\
\hline $\mathrm{HHO} / \mathrm{HEC}$ & $59(8)$ & $6(1)$ & & $62(9)$ & $14(2)$ & & $141(20)$ \\
\hline Light on skid & 0 & $1(<1)$ & & 0 & $6(<1)$ & & $7(1)$ \\
\hline Rugged terrain & $144(20)$ & $28(4)$ & & $67(9)$ & $203(28)$ & & $442(61)$ \\
\hline Isolated terrain & $2(<1)$ & $2(<1)$ & & $14(2)$ & $72(10)$ & & $90(12)$ \\
\hline Inland water/coastal terrain & $88(12)$ & $55(8)$ & & $12(2)$ & $2(<1)$ & & $157(22)$ \\
\hline Offshore terrain & $3(<1)$ & 0 & & $29(4)$ & 0 & & $32(4)$ \\
\hline $\begin{array}{l}\text { Cooperation with other } \\
\text { SAR helicopter }\end{array}$ & $3(<1)$ & $21(3)$ & & $3(<1)$ & $1(<1)$ & & $28(4)$ \\
\hline $\begin{array}{l}\text { Cooperation with other } \\
\text { HEMS helicopter }\end{array}$ & $27(4)$ & $2(<1)$ & & 0 & $1(<1)$ & & $30(4)$ \\
\hline
\end{tabular}

SAR, search and rescue; HEMS, helicopter emergency medical services; IQR, interquartile range. HHO, helicopter hoist operations; HEC, human external cargo operations; N/A, not applicable.

Mission time: Time from takeoff to return (landing) at base.

Negative search: Search without result.

Light on skid: Helicopter evacuation without full touchdown on skid/landing gear.

* Mann-Whitney U test.

${ }^{\dagger}$ Pearson's $\chi^{2}$ test.

The primary objective of the SAR helicopter is to perform SAR missions, and therefore there appears to be a correct application of triage in the use of this service for longer, more complicated SAR missions. The mission ratio for the HEMS helicopter in favor of remote medevac missions with higher NACA scores and a greater need for medical interventions also appears appropriate according to dispatch criteria. However, the need for advanced procedures in all patient groups was low, concurring with other recent studies. ${ }^{21,24}$

In certain systems, HEMS helicopters are the only available service, performing both SAR and HEMS missions, and may also be equipped for hoist operations. ${ }^{25}$ The latter is generally a more efficient method of extraction from difficult terrain or installation but requires other levels of training and possibly different crew composition. ${ }^{17,26}$ We would argue that whether the service is military or civilian, primarily SAR or HEMS, is probably of less importance than equipment, training, and crew composition.

We observed that trauma constituted the dominant mechanism in patients for both services in both SAR and remote medevac missions. This observation was reported earlier, whereas another study reported a dominance of medical complaints. ${ }^{13,18}$ Psychiatric disorders were another major mechanism, especially in SAR. The latter constitutes a substantial proportion of search operations, which are often extensive and time-consuming, involving many agencies. ${ }^{27}$ Patients in SAR missions had lower degrees of severity compared to remote medevac patients. This was to be expected: The focus of a SAR mission is to locate and evacuate individuals before the situation is exacerbated, as opposed to remote medevac, with an already acknowledged illness/injury. Both services had a high proportion of searches with no results. To our knowledge, this aspect of SAR missions has not been reported previously.

The purpose of this research was to study both SAR and remote medevac missions. We observed that the preconceived definitions of these mission types are not as distinctive or descriptive as needed to provide a clear categorization of these often complicated missions. We suspect that many systems and services could opt to label most of the missions included in this study as SAR 
missions. As such, the label "wilderness medicine" could also be applied to define the missions included in this study as many involve searches, rescues, and medical treatment under austere conditions. ${ }^{28}$

There are several limitations to this study. It is an observational study lacking a control group. It is a retrospective study of patient journals, which were manually examined by the researchers. The data were therefore not specifically registered for the purpose of this study. There is a risk of registration bias and also underreporting in this study. More than one third (86 of 237) of SAR missions by the SAR service and over half ( 49 of 85 ) of SAR missions by the HEMS service were negative searches, which could explain why several missions in this category were missing patient data. A comparatively low NACA score in SAR patients in the SAR service reflects a majority of persons with lesser or no injuries, which may explain why the dominating mechanism also was missing in many patients.

\section{Conclusion}

This study found that both SAR and HEMS services perform SAR and remote medevac missions extensively and that mission profiles vary. The SAR service performs longer SAR missions with greater complexity and occurring in more remote terrain, including offshore. Trauma, medicine, and psychiatry were dominating mechanisms in SAR missions for both services, and there are many search missions with no results. The HEMS service performs a greater proportion of remote medevac missions involving more advanced medical procedures and higher NACA scores. Understanding mission profiles of available resources may contribute to an improved coordination and cooperation of these services.

Acknowledgment: The authors thank Svein J. Reid for assistance with map figure.

Author Contributions: Primary author and data collection (BOR); draft and review of manuscript (BOR, $\mathrm{HH}, \mathrm{MR}, \mathrm{OU}, \mathrm{AJK})$; approval of final manuscript (BOR, HH, MR, OU, AJK).

Financial/Material Support: Norwegian Air Ambulance Foundation covers part of the salary of $\mathrm{HH}, \mathrm{OU}, \mathrm{MR}$, and AJK.

Disclosures: BOR is employed in the medical services of the Norwegian Armed Forces. HH is a part-time research fellow at Norwegian Air Ambulance Foundation (NAAF), the parent company of Norwegian Air Ambulance (private limited company, the operating contractor for HEMS Trondheim). MR and AJK are both senior researchers with the Norwegian Air Ambulance Foundation. BOR, OU and AJK all fly with HEMS Trondheim. HH flies with SAR Ørland. MR works for Air ambulance department, Oslo University Hospital.

\section{Supplementary materials}

Supplementary material associated with this article can be found in the online version at https://doi.org/10.1016/ j.wem.2019.02.003.

\section{References}

1. Kruger AJ, Skogvoll E, Castren M, Kurola J, Lossius HM. Scandinavian prehospital physician-manned emergency medical services-same concept across borders? Resuscitation. 2010;81(4):427-33.

2. Faudree LK. Missions, training and equipment: a retrospective view from the 160th SOAR (A). J Spec Oper Med. 2012;12(3):11-8.

3. Diverio S, Barbato O, Cavallina R, Guelfi G, Iaboni M, Zasso R, et al. A simulated avalanche search and rescue mission induces temporary physiological and behavioural changes in military dogs. Physiol Behav. 2016;163:193-202.

4. Butler CR, O'Connor MB, Lincoln JM. Aviation-related wildland firefighter fatalities-United States, 2000-2013. MMWR Morb Mortal Wkly Rep. 2015;64(29):793-6.

5. Clarke JE, Davis PR. Medical evacuation and triage of combat casualties in Helmand Province, Afghanistan: October 2010-April 2011. Mil Med. 2012;177(11):1261-6.

6. Buschmann C, Niebuhr N, Schulz T, Fox UH. "SAR-FirstResponder Sea"-backgrounds to a medical education concept in German SAR service. Int Marit Health. 2009;60(1-2):43-7.

7. Thibodaux DP, Bourgeois RM, Loeppke RR, Konicki DL, Hymel PA, Dreger M. Medical evacuations from oil rigs off the Gulf Coast of the United States from 2008 to 2012: reasons and cost implications. J Occup Environ Med. 2014;56(7):681-5.

8. Heggie TW, Heggie TM. Search and rescue trends and the emergency medical service workload in Utah's National Parks. Wilderness Environ Med. 2008;19(3):164-71.

9. Corniche J, Pasquier M, Yersin B, Kern C, Schoettker P. Helicopter rescue involving the winching of a physician. Air Med J. 2012;31(2):87-91.

10. Haagensen R, Sjoborg KA, Rossing A, Ingilae H, Markengbakken L, Steen PA. Long-range rescue helicopter missions in the Arctic. Prehosp Disaster Med. 2004;19(2):158-63.

11. Maddry JK, Mora AG, Savell S, Reeves LK, Perez CA, Bebarta VS. Combat MEDEVAC: A comparison of care by provider type for en route trauma care in theater and 30-day patient outcomes. J Trauma Acute Care Surg. 2016;81(5 Suppl 2 Proceedings of the 2015 Military Health System Research Symposium):S104-10.

12. Tomazin I, Vegnuti M, Ellerton J, Reisten O, Sumann G, Kersnik J. Factors impacting on the activation and approach times of helicopter emergency medical services in four Alpine countries. Scand J Trauma Resusc Emerg Med. 2012;20:56.

13. Visser JT, Campbell AF. New Zealand land search and rescue operations: an analysis of medical and traumatic conditions. Wilderness Environ Med. 2014;25(4):401-8.

14. Schuurman N, Bell NJ, L'Heureux R, Hameed SM. Modelling optimal location for pre-hospital helicopter emergency medical services. BMC Emerg Med. 2009;9:6.

15. Lesaffre X, Tourtier JP, Violin Y, Frattini B, Rivet C, Stibbe O, et al. Remote damage control during the attacks on Paris: lessons learned by the Paris Fire Brigade and evolutions in the rescue system. J Trauma Acute Care Surg. 2017;82(6S Suppl 1):S107-13. 
16. Prytz EG, Rybing J, Jonson CO. Workload differences across command levels and emergency response organizations during a major joint training exercise. $J$ Emerg Manag. 2016;14(4):289-97.

17. Glomseth R, Gulbrandsen FI, Fredriksen K. Ambulance helicopter contribution to search and rescue in North Norway. Scand J Trauma Resusc Emerg Med. 2016;24(1):109.

18. Declerck MP, Atterton LM, Seibert T, Cushing TA. A review of emergency medical services events in US national parks from 2007 to 2011. Wilderness Environ Med. 2013;24(3):195-202.

19. Bjornsen LP, Solheim AM, Uleberg O, Skogvoll E. Compliance with a national standard by Norwegian helicopter emergency physicians. Air Med J. 2018;37(1):46-50.

20. Osteras O, Brattebo G, Heltne JK. Helicopter-based emergency medical services for a sparsely populated region: a study of 42,500 dispatches. Acta Anaesthesiol Scand. 2016;60(5):659-67.

21. Samdal M, Haugland HH, Fjeldet C, Rehn M, Sandberg M. Static rope evacuation by helicopter emergency medical services in rescue operations in southeast Norway. Wilderness Environ Med. 2018;29(3):315-24.

22. Raatiniemi L, Liisanantti J, Tommila M, Moilanen S, Ohtonen P, Martikainen M, et al. Evaluating helicopter emergency medical missions: a reliability study of the HEMS benefit and NACA scores. Acta Anaesthesiol Scand. 2017;61(5):557-65.
23. von Elm E, Altman DG, Egger M, Pocock SJ, Gotzsche PC, Vandenbroucke JP. The Strengthening the Reporting of Observational Studies in Epidemiology (STROBE) statement: guidelines for reporting observational studies. Bull World Health Organ. 2007;85(11): 867-72.

24. Pietsch U, Knapp J, Kreuzer O, Ney L, Strapazzon G, Lischke V, et al. Advanced airway management in hoist and longline operations in mountain HEMS-considerations in austere environments: a narrative review. This review is endorsed by the International Commission for Mountain Emergency Medicine (ICAR MEDCOM). Scand J Trauma Resusc Emerg Med. 2018;26(1):23.

25. Ausserer J, Moritz E, Stroehle M, Brugger H, Strapazzon G, Rauch S, et al. Physician staffed helicopter emergency medical systems can provide advanced trauma life support in mountainous and remote areas. Injury. 2017;48 (1):20-5.

26. Sherren PB, Hayes-Bradley C, Reid C, Burns B, Habig K. Are physicians required during winch rescue missions in an Australian helicopter emergency medical service? Emerg Med J. 2014;31(3):229-32.

27. Sward DG, Bennett BL. Wilderness medicine. World J Emerg Med. 2014;5(1):5-15.

28. Rodway GW. The foundations of wilderness medicine: some historical features. Wilderness Environ Med. 2012;23 (2):165-9. 